\title{
SITUAÇÃO DAS MULHERES NAS ECONOMIAS EMERGENTES DO SUL: ANÁLISE COMPARADA DA (IN)EFETIVIDADE DAS POLÍTICAS PÚBLICAS DE PROTEÇÃO DA MULHER E DE REDUÇÃO DA DESIGUALDADE DE GÊNERO NA CHINA, ÍNDIA E BRASIL
}

\author{
Diva Júlia Sousa Safe Coelho* \\ Saulo de Oliveira Pinto Coelho**
}

\section{RESUMO:}

A pesquisa realiza estudo comparado das experiências concretas de China, Índia e Brasil acerca da implementação de políticas de proteção da mulher e redução da desigualdade de gênero. Busca superar a comparação puramente nomológica ou doutrinaria, típica da visão clássica do Direito Comparado, em prol de uma comparação das experiências e das realidades. Para tal, lança mão de um complexo de dados coletados nos mais relevantes relatórios sobre o tema no contexto internacional e da literatura sobre o tema nesses países, privilegiando as abordagens oferecidas pelas pesquisadoras e pesquisadores de fato inseridos na realidade de cada um desses países-continentes.

Palavras-chave: BRICs; Direitos das Mulheres; Gênero; Comparação Jurídica; Políticas Públicas

\section{SITUATION OF WOMEN IN BRASIL, INDIA AND CHINA: COMPARATIVE ANALYSIS OF THE (IN)EFFECTIVENESS OF PUBLIC POLICIES FOR WOMEN AND REDUCTION OF GENDER INEQUALITY}

\begin{abstract}
The research consists of a comparative study of the concrete experiences of Russia, China, India and Brazil on the implementation of policies for the protection of women and reduction of gender inequality. It seeks to overcome the purely nomological or doctrinal comparison, typical of the classical view of Comparative Law, in favor of an experiences and realities comparison. To achieve this goal, it uses a complex of data gathered from the most relevant reports on the subject in the international context, as a critical counterpoint, an in-depth study of the existing literature on the subject in each of the countries.
\end{abstract}

Keywords: BRIC; Women's Rights; Gender; Public Policies

\footnotetext{
* Bolsista CAPES do programa de estágio pós-doutoral PNPD, na área de Direito Constitucional Comparado, pela Universidade Federal de Uberlândia - UFU. Doutora em Ciudadania y Derechos Humanos pela Universidad de Barcelona. Mestre em Filosofia Política pela Universidade Federal de Goiás - UFG. Graduada em Direito pela Pontifícia Universidade Católica de Minas Gerais. Membro permanente do Grupo Internacional de Pesquisa em Cultura, História e Estado (GIRCHE) da Universitat de Barcelona- UB. Membro do Grupo de Pesquisa Processo Fraterno e Direito do Agronegócio da UniRV. Membro permanente do Laboratório Americano de Estudos Constitucionais Comparados (LAECC), junto ao CNPq. E-mail: <diva.julia@ hotmail.com>.

** Possui doutorado, mestrado e graduação em Direito pela Universidade Federal de Minas Gerais. Realizou PósDoutorado como bolsista CAPES, na área de Teoria do Direito, junto à Universitat de Barcelona - Espanha. É professor efetivo da Universidade Federal de Goiás (UFG), onde atualmente é Vice-Diretor da Faculdade de Direito (FD-UFG), bem como Coordenador do Programa de Pós-Graduação em Direito e Políticas Públicas (PPGDP-UFG). É professor do Programa de Pós-Graduação Interdisciplinar em Direitos Humanos da UFG. Email: <saulopintocoelho@yahoo.com.br>.
} 


\section{INTRODUÇÃO}

A atual globalização, aceleradora e uniformizadora dos processos produtivos e tecnológicos, tornou por demais próximos e compartilhados os problemas das nações tidas por emergentes, em que pese o eventual desencontro de contextos e de perspectivas a respeito. É imperioso destacar que os países do BRICS, as maiores economias emergentes do mundo, possuem problemas comuns a eles próprios, decorrentes, sobretudo, dos recentes processos de modernização nos quais se viram engajados. Isso não quer dizer que esses problemas se manifestam e se configuram de modo igual, em sua dinâmica e em seus desafios.

A desigualdade, opressão, descriminação e violência contra a mulher é certamente um problema compartilhado por Brasil, Índia e China, países que formam as três maiores economias do hemisfério Sul (assim considerado do ponto de vista geopolítico).

O estudo comparado aqui desenvolvido proporcionou como resultado uma melhor compreensão dos complexos político-sociais e institucionais que, em cada um desses três países, dão os tons e os contornos próprios acerca das dificuldades que enfrentam as mulheres, quanto ao reconhecimento de seus direitos constitucionalmente declarados, nesses países, e das insuficiências, contradições e inefetividades que marcam as políticas públicas de proteção e promoção da mulher nessas nações.

Demanda-se por conhecer melhor os países em desenvolvimento, para além de suas dinâmicas econômicas. Isso inclui conhece-los melhor também em suas dinâmicas e experiências jurídicas, sociais e institucionais. Mas, para suprir essa demanda cognitiva, não basta desenvolvimento de comparações abstratas, meramente nomológicas. Por isso, o contraste crítico que se busca construir no presente texto, notadamente pela busca por utilização de fontes de pesquisa advindas dos próprios países estudados. Isso permite um contraponto duplo: entre o plano do discurso nomológico e o plano da vivência efetiva de direitos fundamentais, nos estudos comparados (no caso o plano efetivo dos direitos das mulheres e seu desrespeito); e, por outro lado, o contraste entre a visão externa, eurocêntrica, desses problemas e as narrativas críticas desenvolvidas intestinamente, nesses países tão complexos.

Essas pesquisas possuem o condão de, além de colaborar para um conhecimento mais adequado dos países com os quais necessariamente interagimos no mundo globalizado, permitir uma autocrítica mais profunda da própria experiência constitucional brasileira; e seus hiatos de efetividade. 
Não há dúvidas de que mesmo os autores mais renomados do Direito Comparado, em geral param numa abordagem mais "clássica" da disciplina sem qualquer aprofundamento na temática da configuração concreta do, podemos assim dizer, estado da efetividade dos direitos fundamentais nestas ordens constitucionais. A pesquisa aqui relatada atua justamente aí, quanto ao tema específico dos direitos da mulher, e busca responder aos anseios dos atuais debates críticos em Direito Comparado, notadamente quanto a necessidade de uma comparação dialogal e diatópica, centrada em experiências concretas. O trabalho, ao não se restringir à literatura europeia e ir ao encontro da produção acerca do tema feita nos próprios países, enfrentou as dificuldades decorrentes das barreiras linguísticas, tendo em vista a diversidade desafiadora das matrizes analisadas, e precisou ancorar-se nas produções exaradas na língua inglesa.

Mais que descrever o discurso nomológico sobre os direitos das mulheres e as políticas de proteção da mulher nos BRICs, a presente pesquisa buscou denunciar o estado de inefetividade desses direitos e dessas políticas, apesar dos esforços existentes.

\section{A situação da desigualdade de gênero e discriminação da mulher na Índia}

Na Índia, às mulheres é garantido pela Constituição do país o direito à igualdade (artigo 14), o que se desenvolve no próprio texto constitucional nas mais diversas disposições (artigos 15, 16, 19, 21, 23, 38, 39, 42, 44, 243D e 243T), com acentuada densificação normativa, ao menos do ponto de vista da quantidade de normas (SINGH, 2013). Afinal, inúmeras são as leis e políticas aprovadas pelo Estado indiano referentes às mulheres, tais como a Lei de Proibição do Dote (1961), a Lei indiana sobre Casamentos (1955), a Lei indiana sobre sucessões (1956), a Lei de Proteção das Mulheres contra a Violência Doméstica (2005), a Lei sobre Assédio Sexual de Mulheres no Ambiente de Trabalho (Prevenção, Proibição e Indenização) (2013), a Lei de Divórcios (1969), a Lei de Igualdade Salarial (1976), a Lei sobre mulheres muçulmanas (proteção dos direitos de divórcio) (1986), a tipificação específica de crimes contra as mulheres (seção 376, 363-373, 302/304-B, 498 A, 354 e 509 do Código Penal Indiano), e a Política Nacional para o Empoderamento das Mulheres (2001), dentre outras.

Contudo, conforme já argumentou convincentemente Robert D. Baird (1999), de uma perspectiva jurídico-histórica, o texto constitucional em vigor por mais de 60 anos afirma um moderno e progressista sistema de valores, especialmente no que diz respeito às mulheres, 
em claro conflito para com o daquele da ainda forte e presente normatividade tradicional indiana, em que pese seu inconteste pluralismo (AMBEDKAR, 1980). Assim, tal qual colocado por Michael Dusche, grosso modo, a maioria dos hindus, muçulmanos, cristãos, sikhs, urbana, rural, ou tribal, tende a concordar que o lugar da mulher é em casa, e não em público, e, caso ela queira se aventurar, que isso aconteça preferencialmente de dia, vestida em roupas modestas, e idealmente acompanhada por outros membros da família que possam agir como seus protetores (DUSCHE, 2014, p. 229 et seq.)

Nas palavras de Sudhir Kakar, a sociedade indiana tradicionalmente define a pessoalidade de um indivíduo (isto é, sua dignidade enquanto pessoa) a partir de seus relacionamentos, e não de sua individualidade. Assim, enquanto mãe, filha, irmã ou esposa, a mulher é incontestavelmente digna de respeito. Contudo, fora dessas categorias e contextos, a mulher ou é uma "fềmea", um "bhog ki cheez" (um objeto de prazer), ou, por estar deslocada de suas obrigações, está sujeita à punição, podendo se dar, inclusive, na forma de violência sexual (KAKAR, 2013). Esse conflito entre relacionamento e individualidade, ou, seguindo a sugestão do próprio Michael Dusche (2014), entre hierarquia e equidade está ao centro da situação das mulheres na Índia, construindo e influenciando o horizonte cultural de reprodução e efetivação do Direito a esse respeito.

Nas sensíveis palavras de Anju Singh (1998), as mulheres na Índia, como em outros lugares, é verdade, nascem para lutar por seus direitos desde o início, constantemente silenciadas emocional, familiar, religiosa e economicamente. Isto se ilustra, por exemplo, com a complexa prática dos dotes. Basicamente, a realização de transações de caráter econômico e financeiro entre a família da noiva e a família do noivo, consistindo na doação de presentes e dinheiro por parte da primeira à segunda, legalmente proibida, mas ainda muito praticada (GUPTA, 2003, p. 85-88). Em 2010 foram registrados 5.182 casos da prática, criminalizada desde 1961 (BEGUM, 2014, p. 118 et seq.). Outra confirmação desse estado de coisas é a visão estereotipada que se tem da mulher na sociedade indiana, que faz com que elas sejam socialmente preteridas antes mesmo do nascimento, em muitas situações, sendo comum as narrativas de gravidez de meninas como um infortúnio ocorrido ao casal.

No censo nacional realizado em 2011, constatou-se que a razão de sexo na Índia é de 1000 homens para 943 mulheres. A razão de sexo infantil, por sua vez, é de 1000 para 919. Isso se dá por consequência dos valores (especialmente financeiros) negativos atribuídos ao nascimento de uma menina. Enquanto um menino ao crescer, acredita-se, contribuirá para o 


\section{SITUAÇÃO DAS MULHERES NAS ECONOMIAS EMERGENTES DO SUL: ANÁLISE COMPARADA DA (IN)EFETIVIDADE DAS POLÍTICAS PÚBLICAS DE PROTEÇÃO DA MULHER E DE REDUÇÃO DA DESIGUALDADE DE GÊNERO NA CHINA, ÍNDIA E BRASIL}

sustento da família, e, ao se casar, receberá o dote respectivo, uma menina será mais uma pessoa para sustentar, com a família tendo de dispender ela própria de recursos, por sua vez, para pagar seu dote quando ela se casar. Assim, o país enfrenta um sério problema de infanticídios e fetocídios baseados em gênero: "é melhor gastar 500 rúbias agora no teste do que 50.000 em um dote para a filha" ${ }^{1}$, pensam muitos na Índia. Malgrado os incentivos financeiros oferecidos pelo governo para a realização do parto em hospitais públicos e pelo nascimento de meninas, não há grandes transformações dessa situação nas últimas duas décadas (LIVNE, 2017).

O problema dos dotes não se restringe ao nascimento, contudo. Segundo os levantamentos de Eleonora Corsini, quando esse é considerado insuficiente ou insatisfatório, é comum que o marido abuse ou violente a esposa continuamente, até que ela seja morta, normalmente incendiada, ou cometa suicídio (CORSINI, 2017). A prática é tipificada pelo Código Penal Indiano, em seu artigo 304 (B) ${ }^{2}$. Todavia, no ano de 2011, o Serviço Nacional de Registros Criminais da Índia registrou 8.618 mortes femininas relacionadas a dotes. Já o Conselho Asiático das Mulheres sobre Direitos Humanos estima que 25.000 mulheres entre 15 e 24 anos são mortas anualmente pelo mesmo motivo (LIVNE, 2015).

Os números também são chocantes no que diz respeito a casos de estupro. Segundo o Serviço Nacional de Registros Criminais, 24.206 casos foram registrados no ano de 2011. Mais assustadora é a maneira pela qual a sociedade e mesmo o judiciário indiano interpretam tais acontecimentos.

Em janeiro de 1996, relata Michael Dusche, uma garota de dezesseis anos de Suryanelli, Kerala, ao fugir com seu namorado, sendo posteriormente por ele abandonada, caiu nas mãos de um casal que a estuprou, confinou, e agenciou como suposta prostituta para quarenta outros homens em um período de quarenta dias. Em 2000, a corte local sentenciou

\footnotetext{
${ }^{1}$ Conforme relata Anantanad Ramechan, um proeminente teólogo do hinduísmo, dos 13.400 abortos realizados por uma clínica especializada de Nova Delhi entre 1992 e 1993, 13.338 eram de fetos femininos. Outro estudo, citado pelo autor, mostra que dos 8.000 fetos abortados no estado de Maharashtra, 7.999 eram femininos. Para o autor, tal prática é a principal causa da atual razão de sexo na Índia. (cf. RAMECHAN, 2001).

${ }^{2}$ Fogões abastecidos por querosene são bem comuns na Índia, tal qual o hábito de guardar combustível em reserva. Como o fogo não só elimina a vítima como virtualmente todas as evidências da morte, há uma predileção por tal curso de ação em crimes domésticos relacionados a dotes. Assim, encontra-se disposto o seguinte no artigo 304 (B) do Código Penal Indiano (1960): "Quando a morte de uma mulher é causada por queimaduras ou ferimentos corporais ou ocorre de outras formas que não em circunstâncias normais dentre os 7 primeiros anos de casamento e é mostrado que imediatamente antes da morte ela foi submetida a crueldade e assédio pelo marido ou por qualquer parente seu por, ou em conexão a, qualquer demanda relacionada ao dote, essa morte deverá ser chamada 'morte dotal', e seu marido ou relativo deverá ser julgado por ter causado sua morte."
} 
trinta e seis dos quarenta homens e a mulher como culpados, condenando-os rigorosamente. A decisão foi recorrida e em 2005 a Alta Corte de Kerala absolveu trinta e cinco dos acusados argumentando pela possibilidade da garota ter consentido com os atos sexuais. Os juízes assim decidiram em razão do "caráter" da vítima, que, ao ter praticado atos sexuais com seu namorado antes do casamento, se mostrou desviante do esperado de uma garota inocente de sua idade. Em outras palavras, ela seria a culpada por outros homens se aproveitarem de sua "promiscuidade". Em 2013 a Suprema Corte da Índia declararia como chocante tal julgamento, determinando sua revisão. Em 4 de abril de 2014, uma nova bancada da Alta Corte de Kerala condenou um dos acusados à prisão perpetua, enquanto outros 22 foram condenados a longos anos de encarceramento. Sete foram absolvidos, e cinco morreram durante o julgamento. Ainda assim, a defesa alegou que a vítima teria sido relapsa, podendo ter escapado durante o período em que ficou cativa (DUSCHE, 2014).

Após o estupro coletivo de uma estudante de 23 anos em Delhi, no dia 16 de dezembro de 2012, a opinião pública internacional se voltou completamente para a questão na Índia. O resultado da pressão internacional foi a constituição de um comitê pela Suprema Corte da Índia, liderado pelo Justice J. S. Verma (2013). No dia 23 de janeiro de 2013, o comitê publicou um relatório extenso sugerindo uma série de reformas na atual legislação, dentre elas, por exemplo, a criminalização do estupro conjugal (recomendação que até a presente data não foi seguida). Como a postura inicial da bancada da Alta Corte de Kerala evidencia, a visão tradicionalista a respeito do lugar das mulheres na Índia não se restringe ao interior e às margens da sociedade, alcançando, assustadoramente, uma parte da elite do Estado indiano.

Não obstante, conquistar publicidade às leis de proteção constitui por si só um sério obstáculo no combate à desigualdade de gênero na Índia. Por exemplo, no tocante ao direito de família ${ }^{1}$, Upendra Baxi, comentando estudo realizado por B. B. Chatterjee quanto ao acesso à informação legal em quatro vilarejos no distrito de Banaras, aponta que os entrevistados não tinham nenhum conhecimento a respeito da idade mínima legal para casamento, ou que a prática dos dotes havia sido proibida. Pouco sabiam a respeito das

\footnotetext{
${ }^{1}$ Ainda que muitas das controvérsias nessa área sejam consequências da atual e incontornável estrutura do sistema jurídico indiano, em que se permite a vigência, sob a égide constitucional, de diversas ordens normativas religiosas, embasadas no princípio da personalidade. Assim, há um constante jogo político, com uma intensa pressão por parte das respectivas comunidades religiosas para manterem aquém da legislação estatal uma série de matérias reguladas por suas próprias normativas pessoais, como sucessões, casamento, divórcio, propriedade. (cf. COSSMAN, 1993; NUSSBAUM, 2001).
} 
normativas referentes a divórcio. Quanto à Lei de Sucessões Hindus, apenas 12 dos 200 entrevistados responderam ter algum conhecimento a respeito, com a única exceção concernindo a provisão referente ao direito de herança que passaram a ter as mulheres. Segundo Baxi, enquanto $68 \%$ dos respondentes pertencentes às castas mais elevadas se opunham veementemente à medida, $71 \%$ dos demais a viam favoravelmente nas demais castas (BAXI, 2014).

As mulheres na Índia também enfrentam dificuldades no acesso à educação e perante o mercado de trabalho (JAVEED; MANUHAAR, 2013, p. 06-12), mesmo existindo legislações e políticas públicas especificas para ambos os correlatos problemas, bem como um número considerável de decisões judiciais a respeito. Assim segundo o Censo de 2011 da Índia (2013): o grau de alfabetização é de $65,50 \%$ entre as mulheres, contra $82,10 \%$ entres os homens (com um índice de abandono dos estudos $10 \%$ maior entre as mulheres do que entre os homens); $73,78 \%$ da força de trabalho rural é composta por homens, contra $26,22 \%$ de mulheres. Esses números, que deveriam ser melhores em contextos urbanos, não o são: a relação dos postos de trabalho no meio urbano é de $84,76 \%$ para $15,24 \%$, com mulheres recebendo salários, em média, entre 20 e $60 \%$ menores que os dos homens. O resultado é um círculo vicioso em que as mulheres, por terem, comparativamente, menor preparo profissional e nível escolar que os homens, não conseguem competir por vagas no mercado de trabalho, muito menos nos centros urbanos. Consequentemente, $94 \%$ da força de trabalho feminina é constituída por trabalhadoras autônomas, localizada, em sua maioria, no campo (cf. COSSMAN; KAPUR, 1993).

Percebe-se, portanto, um sério problema de efetividade, constituído de maneira extremamente complexa, por fatores que vão desde a falta de publicidade dos progressos legislativos, passando pelas tensas relações entre o direito estatal e a série de ordens normativas de caráter tradicional, à "baixa constitucionalidade" (baixa permeabilidade à linguagem constitucional) dos agentes políticos e estatais quando o assunto diz respeito às mulheres, imersos culturalmente na hierarquia patriarcal ainda presente da sociedade indiana. É preciso ressaltar o contexto em que essa verticalização entre homens e mulheres acontece na Índia. Em que pese as disposições constitucionais claras a respeito, parte do estigma social das castas e tribos intocáveis permanece, a tornar a situação das mulheres pertencentes a essas castas ainda mais difícil (cf. JUSTIN, 2016, p. 135 et seq.). 
É possível identificar traços dos estereótipos mortais exigidos às mulheres indianas na própria legislação, em várias distinções construídas em sede de direito criminal, direito de família, e mesmo em direito das sucessões. No último caso, e por exemplo, malgrado a mulher hoje ter direito à herança, seu quinhão parte daquilo que é de patrimônio do pai especificamente (podendo ele, caso queira, excluí-la por testamento), e não da família como um todo, enquanto os homens recebem parcela da "propriedade ancestral", conjuntamente ao quinhão correspondente ao patrimônio do pai (COSSMAN; KAPUR, 1993).

Parcialmente é possível atribuir tal estado de coisas à falta de representatividade política das mulheres. A Índia se encontra em $130^{\circ}$ lugar no ranking do Índice de Desigualdade de Gênero construído pela Organização das Nações Unidas (2014). Enquanto $56,6 \%$ da população masculina possui escolaridade igual ou superior ao segundo grau, apenas $27 \%$ das mulheres têm nível de escolaridade semelhante (entre 2005 e 2014). Já 79,9\% da força de trabalho masculina está inserida no mercado de trabalho, contra 27,0\% da feminina (em 2013). E, por fim, somente 12,2\% dos assentos parlamentares são ocupados por mulheres.

Tal déficit democrático (considerando que quase metade da sua imensa população, de 1.326.801.576 pessoas em 2016, é composta por mulheres) já foi identificado como um problema por parcela da sociedade indiana. Desde 1996, observa-se tentativas de aprovar uma emenda constitucional reservando 33\% dos assentos no parlamento nacional (Lok Sabha) e em assembleias estatais para mulheres, com a última tendo ocorrido no ano de 2010. A resistência política a tanto, contudo, é surpreendente. Passando por representantes do movimento feminista a políticos das castas excluídas, bem como aqueles de alinhamento claramente conservador, o projeto é criticado, desde seus fundamentos, enquanto ação afirmativa, até quanto às suas possíveis consequências e mecanismos propostos para a seleção das futuras representantes ( $c f$. RADALL, 2006, p. 65-78)

\section{A situação da desigualdade de gênero e discriminação da mulher na China}

Qualquer que seja o posicionamento a respeito do legado do comunismo na China, foi em sua decorrência e, consequentemente, nos últimos 50 anos, que as mudanças mais dramáticas ocorreram em relação à vida das mulheres no país. É com tais palavras que 
Anne M. Han sugere o ano de 1949 como um divisor de águas para a situação das mulheres na China ( $c f$. HAN, 2001).

Nesse sentido, pode-se dizer que mesmo com o início do processo de modernização ao final do período dinástico, com o advento da Revolução, apenas em 1921, com a criação do Partido Comunista Chinês e suas ações, a questão das mulheres passou a ter relevância no espaço público, até então considerada de pouca relevância. Por exemplo, já em 1911, o governo republicano que se seguiu ao fim da Dinastia Qing, inicialmente negara às mulheres o direito de voto (BEHAN, 1981). E assim, em 1949, com a ascensão de Mao TséTung e a implementação de reformas de cunho marxista, uma série de medidas foram introduzidas, inclusive a nível constitucional, como nos textos constitucionais de $1949^{1}$ e 1954, bem como, a nível infraconstitucional, notadamente a muito estudada Lei sobre Casamentos de $1950^{2}$ - com vistas a erradicar qualquer tipo de discriminação de gênero até então legalizadas.

De cidadãos de segunda-classe, na melhor das hipóteses, a detentoras de "metade do céu", na famosa expressão de Mao Tsé-Tung ( $c f$. ZUO, 2016), com o amparo pela ideologia oficial maoísta que via nas mulheres exemplos de heroínas, guerreiras e camaradas operárias, as mulheres na China, especialmente nos centros urbanos e na estrutura estatal, galgariam cada vez mais espaço na sociedade chinesa. Contudo, em que pese o caos e o terror da Revolução Cultural, muitos estudiosos constatam retrocessos na situação das mulheres na China após 1978, com a série de reformas introduzidas inicialmente sob a liderança de Deng Xiaoping ( $c f$. HERSHATER, 2016).

Ainda que a Constituição de 1982 se mantenha na tradição estabelecida, nela se declarando formalmente a igualdade entre homens e mulheres, em todas as esferas da vida, sejam estas políticas, econômicas, culturais, sociais ou familiares (artigo 48 (1)), inclusive se

\footnotetext{
${ }^{1}$ Por meio do artigo $6^{\circ}$ de seu famoso Programa Comum, o Partido Comunista Chinês assim declarou em 1949: "A República Popular da China deverá abolir o sistema feudal que mantém as mulheres em servidão. As mulheres deverão gozar de direitos iguais aos homens na vida política, econômica, cultural, educacional e social. A liberdade matrimonial para homens e mulheres deverá ser posta em prática" [tradução livre]. (PARTIDO COMUNISTA CHINÊS, 1949).

${ }^{2}$ Nas palavras de Gail Hershatter: "A Lei sobre Casamentos da República Popular da China de 1950 aboliu o 'casamento feudal' e o 'casamento por compra', estabelecendo a liberdade escolha como um princípio fundamental. A lei também afirmava o direito a divórcio de adultos, independentemente de quaisquer restrições. " (HERSHATTER, 2007, p. 16). A natureza radical das mudanças propostas, continua a autora, pode ser vista parcialmente nas resistências profundas que suscitou. Por exemplo, por terem adquirido uma esposa para seu filho e uma nora para eles próprios a preços consideráveis, muitos pais, especialmente em áreas rurais, se sentiam ultrajados diante da hipótese de perder seu investimento por causa de um divórcio. Assim, as tentativas por parte do governo de colocar a lei em efetividade foram tateantes.
} 
determinando como dever do Estado a proteção dos direitos e interesses das mulheres, bem como da igualdade salarial e de ingresso no serviço público (artigo 48 (2)), a densificação infraconstitucional, a nível legislativo e administrativo, e a efetividade desses direitos fundamentais têm sido ambivalente, no mínimo.

Assim, no ranking do Índice de Desigualdade de Gênero ${ }^{1}$ construído pelo Programa de Desenvolvimento da Organização das Nações Unidas, em 2014 a China se encontrava na quadragésima posição (a melhor entre os quatro países pesquisados nesse estudo). Isso, em face, dentre outros, dos seguintes dados: no ano de 2014 , apenas $23,6 \%$ dos assentos parlamentares eram ocupados por mulheres; apenas 58,7\% das mulheres na China possuíam escolaridade superior ou igual ao segundo grau, em contraponto a $71,9 \%$ dos homens entre 2005 e 2014; apenas 63,9\% da força de trabalho feminina está inserida no mercado de trabalho, contra 78,3\% da força de trabalho masculina em 2013. Pese à sua posição ligeiramente superior a do Brasil e da Rússia e significativamente melhor que a da Índia, a situação da mulher na China ainda é bastante desigual e os motivos dessa desigualdade merecem ser analisados.

Tais estatísticas não deixam de espelhar três dos principais problemas hoje enfrentados pelas mulheres na China: a visão estereotipada da mulher a informar a produção jurídica, a nível legislativo e administrativo, especialmente no âmbito do direito trabalhista (WEI, 2009, p. 263-270); as práticas discriminatórias daí resultantes no mercado de trabalho; e o consequente êxodo urbano, com muitas mulheres em situação de "migração forçada" ou de marginalização, ao se verem sem alternativa, senão retornar ao interior, ou recorrerem à prostituição, para viver.

Do período da Reforma em diante, como que a negar a doutrina maoísta de outrora, denunciada oficialmente como ingênua e contraproducente, as mulheres deixarão de ser vistas como idênticas aos homens, inclusive no que diz respeito às capacidades laborais. Ao contrário, passa-se a afirmar sua fragilidade e propensão natural à maternidade e ao cuido do lar. Estes valores se encontram positivados: em uma série de exigências legalmente impostas aos empregadores para a contratação de mulheres, tais como a construção de creches e berçários, a concessão de licença-maternidade por período não inferior que 90 dias, e várias outras medidas voltadas para a seguridade social das crianças; na vedação do emprego de mulheres em atividades consideradas de "alta intensidade" e em atividades mineratórias

\footnotetext{
${ }^{1}$ ORGANIZAÇÃO DAS NAÇÕES UNIDAS (ONU). Gender Inequality Index. 2014. Disponível em: <http://hdr.undp.org/en/composite/GII> Acesso em: 20 jan. 2016.
} 


\section{SITUAÇÃO DAS MULHERES NAS ECONOMIAS EMERGENTES DO SUL: ANÁLISE COMPARADA DA (IN)EFETIVIDADE DAS POLÍTICAS PÚBLICAS DE PROTEÇÃO DA MULHER E DE REDUÇÃO DA DESIGUALDADE DE GÊNERO NA CHINA, ÍNDIA E BRASIL}

subterrâneas, bem como de seu trabalho em locais de elevada altitude, clima frio, ou águas frias quando menstruadas ${ }^{1}$; na utilização de vários conceitos indeterminados relativos à permissão ou não de certas atividades laborais para mulheres, corroborados por período considerável de práticas discriminatórias ${ }^{2}$.

Logo, ainda que algumas das referidas medidas legais possam ser vistas como “humanizantes”(OGLETREE, 2002, p. 77-8) pela opinião pública internacional, estando presentes em inúmeros países, na China o mercado não compartilha de semelhante opinião, nem se encontra sujeito a mecanismos aptos a forçá-lo nesse sentido. Por consequência, as mulheres além de se verem preteridas, dada sua reduzida competitividade ${ }^{3}$ em razão de tais obrigações a ela atreladas, interpretadas como fruto de um paternalismo protecionista por Ogletree e Silva-de-Alwis (2002), quando empregadas (isto é, naqueles ramos e atividades para os quais podem sê-lo), dificilmente se encontram inseridas em ambientes laborais legalmente adequados, e, por fim, com dificuldades de fazê-los se conformar com a lei.

O sofrimento de discriminação por razões de gênero, por sua vez, se insere em um contexto maior. O combate a práticas discriminatórias, inclusive em outras áreas, como educação ${ }^{4}$ e transporte público, e com base também em outros fatores, que vão desde altura e

\footnotetext{
${ }^{1}$ Vedações previstas nos artigos 59 e 60 da Lei Laboral da República Popular da China; $c f$. REPÚBLICA POPULAR DA CHINA. Labour Law of the People's Republic of China. 5 de junho de 1994. Disponível em: <http://www.npc.gov.cn/english npc/Law/2007-12/12/content_1383754.htm>. Acesso em: 20 jan. 2017.

2 Por exemplo, assim se dispôs por meio do art. 23 da Lei de Proteção aos Direitos e Interesses das Mulheres: "Com exceção de tipos especiais de trabalho ou cargo inapropriados às mulheres, nenhuma unidade poderá, ao empregar funcionários e trabalhadores, se recusar a empregar mulheres por razões de sexo ou aumentar as exigências curriculares para a contratação de mulheres". (REPÚBLICA POPULAR DA CHINA. Law on the Protection of Women's Rights and Interests of the People's Republic of China, 1992) [Tradução livre]. Segundo Burnett: "A Lei de Proteção dos direitos e interesses das mulheres tornou mais difícil para as mulheres serem contratadas na China. Ao permitir que os empregadores recusassem a contratação de mulheres para atividades que thes fossem inapropriadas, ela criou uma abertura para que os empregadores as discriminassem, podendo-se argumentar por serem violações da Constituição". (BURNETT, 2010, p. 305).

${ }^{3}$ Anne M. Han se refere a uma pesquisa realizada pela Federação de Sindicatos de Toda China com 660 fábricas, empregando 15.000 trabalhadores no total, em que apenas 5.3\% dos empregadores respondentes se mostraram inclinados a contratar mulheres para posições que fossem adequadas para ambos os sexos. A razão para tanto, continua a autora, é primariamente econômica. Assim, calcula-se que os custos com gravidez, trabalho de parto e licença-maternidade giram em torno de 1.259 Yuan por trabalhadora. (Cf. HAN, Anne M. Holding-up more than half the sky: marketization and the status of women in China. International Journal of Contemporary Legal Issues, $\left.\mathrm{n}^{\circ} 11, \mathrm{p} .791-810,2001\right)$.

${ }^{4}$ Segundo Anne M. Han, as discrepâncias entre homens e mulheres no mercado de trabalho chinês começam desde a educação. Assim, em que pese a educação fundamental compulsória existir na China, atualmente as escolas vêm cobrando taxas cada vez mais altas por livros e "extras". Consequentemente, especialmente no campo, muitas crianças têm abandonado a escola, com a autora se referindo a dados de 1990, quando 4.8 milhões de crianças, em sua maioria de áreas rurais, abandonaram o estudo, dentre as quais, $80 \%$ eram meninas. Corrobora com tais resultados relatório governamental citado pela autora, no qual se aponta que entre os analfabetos e semianalfabetos na China até o ano de 1994, 70\% são mulheres. Essas tendências se repetem no nível superior, com as mulheres podendo concorrer a apenas um terço das vagas das universidades. ( $c f$. HAN, 2001).
} 
aparência à etnia, não foi um tema relevante para o discurso oficial chinês nos últimos quinze anos. E, malgrado sua ocorrência constante e estrutural na China, entre 2000 e 2011 foram apresentados judicialmente apenas 92 casos envolvendo discriminação. Segundo pesquisa realizada pela Universidade de Ciência Política e Direito da China, dos respondentes, 85,5\% disseram já ter sofrido discriminação, 50,5\% disseram ser discriminação um assunto sério, e apenas 6,6\% afirmaram não existir qualquer discriminação na China (LU, 2015).

Nesse sentido, no que diz respeito às mulheres e à discriminação no mercado de trabalho, o número insignificante de litígios judiciais se dá prioritariamente, na opinião de Jiefeng Lu (2015), por motivos do escopo de aplicabilidade e da procedimentalidade das normativas relevantes, ou seja, se remetem a dificuldades operacionais e de eficácia da legislação.

Primeiro, não existe nenhuma lei especificamente dedicada ao combate à discriminação no mercado de trabalho, o qual é, normativamente, da perspectiva dos trabalhadores regido em três grandes categorias e dois regimes laborais: empregados (contratados por empresas, e regulados pela Lei Laboral Chinesa), servidores públicos (selecionados pelo Estado, e regulados pela Lei dos Servidores Públicos Chinesa), e funcionários de instituições públicas (organizações prestadores de serviços públicos, tais como educação, cultura, higiene etc., estabelecidas por órgãos públicos e outras entidades com recursos estatais, regulados ou pela Lei Laboral ou pela Lei de Serviços Públicos chinesas). Ambos os regimes laborais, contudo, têm seus problemas no que diz respeito à discriminação.

No caso do regime estabelecido pela Lei Laboral Chinesa, sua aplicabilidade se restringe a empregados e empresas vinculados contratualmente (artigo 2). Assim, em que pese as diversas disposições contidas no corpo do texto vedando práticas discriminatórias, nenhuma delas pode ser utilizada como fundamento para mover uma ação contra a empresa discriminante, quando os atos ocorrerem justamente no momento da contratação, dada a ausência de vínculo contratual. A inadequação hermenêutica desse entendimento é patente, e de consequências graves, diante da concentração de práticas discriminatórias justamente na fase de contratação. Denunciativo de tal estado de coisas é a ausência de qualquer referência às situações pré-contratuais em todas as ações judiciais movidas por discriminação trabalhista entre 2000 e 2011.(LU, 2019) 
Tal como revelam os estudos de Jiefeng Lu, padrão semelhante é perceptível no que diz respeito ao serviço público. Mais uma vez, a discriminação acontece basicamente no processo de recrutamento, com muitas das características exigidas e avaliadas não tendo nenhuma relação para com o serviço propriamente, tais como idade, altura, aparência, estado civil, afiliação política etc. Não obstante, ainda que, diferentemente da situação anterior, uma candidata vítima de discriminação possa mover uma ação contra o governo, com base no artigo 2 da Lei de Processo Administrativo da República Popular da China ${ }^{1}$, por meio do qual se determina que qualquer cidadão, pessoa jurídica, ou organização tem o direito de processar o governo ou as agências governamentais, desde que demonstranto a violação de seus direitos e interesses por uma "ação administrativa concreta", a maioria das cortes, segundo Jiefeng Lu (2009), têm recusado tais pleitos, argumentando não ser o referido recrutamento uma "ação administrativa concreta".

Zhou Wei (2003), considera sintomático do atual contexto a presença invariável da referência ao Artigo 33 (2) da Constituição de 1982 como fundamento para todas as ações movidas contra práticas discriminatórias (inclusive aquelas referentes a discriminação de gênero, independentemente das provisões específicas a respeito encontradas na Constituição, como, por exemplo, a do artigo 48). Considerada pela jurística chinesa como a "cláusula de proteção da igualdade”, nela se lê: "Todos os cidadãos da República Popular da China são iguais perante a lei. Todos os cidadãos gozam dos direitos e ao mesmo tempo precisam cumprir com os deveres prescritos pela Constituição e pela lei”. Todavia, como discutido, nos apartados anteriores, o judiciário na China é fortemente influenciado a ignorar o texto constitucional, seja em suas decisões, seja como fundamento para a exigibilidade de direitos. E, mais ainda, hodiernamente na China, a eficácia horizontal dos direitos fundamentais (entendida enquanto sua aplicabilidade direta a relações estabelecidas entre particulares) não é questão pacificada, com parcela considerável da dogmática constitucional argumentando pela inaplicabilidade do texto constitucional em litígios entre particulares.

Logo, diante da ausência de institucionalização na China da possibilidade de discussão pública de discrepâncias entre os direitos fundamentais assegurados no texto constitucional e a particular interpretação deles efetivada nas políticas públicas determinadas pelo Congresso Nacional do Povo e pelo Conselho de Estado, é difícil vislumbrar como tais

\footnotetext{
${ }^{1}$ REPÚBLICA POPULAR DA CHINA. Administrative Procedure Law of the People's Republic of China. 4 de abril de 1989. Disponível em: 〈http://www.china.org.cn/english/government/207336.htm〉. Acesso em: $21 \mathrm{de}$ janeiro de 2017.
} 
direitos de dignidade se veriam caracterizados pela necessária exigibilidade, aí pressuposta a capacidade de se fazer valer, por meio da devida procedimentalidade, inclusive a interpretação da mulher quanto a seus direitos, no debate público.

\section{A situação da desigualdade de gênero e discriminação da mulher no Brasil}

A cultura brasileira no que diz respeito às mulheres se constitui de várias hierarquias herdadas de múltiplas origens, desde a doutrina católica, passando pela cultura ibéria. Marcada por estruturas patriarcais, as posições a serem assumidas e desempenhados por cada gênero estão intimamente ligados à vida sexual e familiar, com o papel da mulher, vinculado tanto ao seu círculo reprodutor como à sua relação com o homem, chefe da família. Assim, prioritária e socialmente, espera-se da mulher que assuma o papel de esposa, mãe e doméstica (ONSRUD; PAIXÃO; NICOLS, 2005).

Até recentemente, tal horizonte de sentido teve influência determinante na produção legislativa do país, como, por exemplo, nas inúmeras restrições referentes a condições de trabalho e exercício de atividades no que diz respeito às mulheres (LOPES, 2006, p. 405 et seq.) Nesse sentido, a Constituição Federal de 1988 é corretamente laureada como inconteste marco de ruptura, ao explicitamente assumir a igualdade entre os sexos, dando azo a uma série de políticas públicas voltadas especialmente para a concretização dessa igualdade no âmbito trabalhista. Por outro lado, em que pese os méritos do texto constitucional, no que concerne especialmente à violência doméstica, e mesmo quanto à desigualdade, seja salarial, seja de participação no mercado de trabalho, muitas têm sido as dificuldades de sua efetivação perante a sociedade brasileira. Assim, até recentemente, tanto a mulher como a violência a contra ela praticada foram relegadas à intimidade do lar, percepção que, mesmo após 1988, demorou a ser extirpada dos textos legais e ainda hoje se vê presente em parte do judiciário e da Administração Pública, mesmo com os contrapontuais avanços.

Sintomaticamente, o Brasil, em 2014, ocupava a alarmante $97^{\mathrm{a}}$ posição no ranking estruturado com base no Índice de Desigualdade de Gênero calculado pela Organização das Nações Unidas. Apenas 9,6\% dos assentos parlamentares eram ocupados por mulheres em 2014. No entanto, por um lado, 54,6\% das mulheres no país possuíam pelo menos o segundo grau em nível de escolaridade, contra 52,4\% dos homens entre 2005 e 2014; por outro, apenas $59,4 \%$ da força de trabalho feminina estava inserida no mercado de trabalho em 2013, contra $80,8 \%$ da masculina. 
A violência contra a mulher é um tema marcante do cenário brasileiro de desigualdade de gênero. Entre 1980 e 2010 estima-se que 92.000 mulheres foram assassinadas no Brasil. Se à primeira vista tais mortes parecem de pouco significado em um universo no qual representam apenas $10 \%$ do total de assassinatos, conforme relatam Stela Nazareth Meneghel e Vania Naomi Hirakata (2011), deve-se, contudo, levar em consideração que desse número $42 \%$ ocorreram em ambientes domiciliares, contra apenas $14 \%$ das mortes masculinas. Corroborando com tais dados, das 51.000 ocorrências hospitalares por mulheres vítimas de violência física em 2011, $22 \%$ dos culpados eram pais das vítimas, e 15\% companheiros atuais ou anteriores.

Tais números, portanto, persistem, apesar do contexto de 20 anos de políticas especificamente voltadas para o combate da violência contra a mulher. Persistência que, em alguma medida, não deixa de parcialmente se afirmar com base nos erros e deficiências normativo-institucionais desse trajeto. Cinco são seus marcos legais, quais sejam, as Leis $n^{\circ}$ 9.099/1995, 10.455/2002, 10.778/2003, 10.886/2004, e 11.340/2006.

Com a primeira criou-se cortes especializadas em crimes de pequena ofensividade (o que, em geral, se afere no sistema jurídico brasileiro com referência à duração da pena atribuída), introduzindo a possibilidade de reconciliação entre vítima e agressor, bem como da suspensão condicional do processo. Em razão da maioria das denúncias relacionadas a violência doméstica serem de condutas criminosas penalizadas pela privação da liberdade por até 02 anos, uma parcela significativa desses casos passou a ser julgada perante as referidas cortes especializadas, terminando, em sua maioria, em transações penais, sem condenação.

Conforme denunciam Ana Lucia Sabadel e Dimitri Dimoulis (2014), o despreparo dos magistrados se fez notável, mais ainda quanto às problemáticas em torno das questões de gênero, assomando-se relatos de soluções inadequadas, com as vítimas sendo forçadas a aceitarem indenizações irrisórias, e algumas disparatadas decisões, como a que determinou que o acusado levasse a vítima para jantar ou lhe entregasse flores. Do mapeamento das decisões, concluem os autores, percebe-se uma "reprivatização" dos conflitos, reforçando a ideia patriarcal de que eles concerniam às partes envolvidas tão somente.

As duas sucessivas novidades legislativas vieram com a finalidade de adaptar os procedimentos da normativa anterior à realidade da violência doméstica, mas com pouco sucesso. No primeiro caso, a Lei n 10.455 introduziu a possibilidade da adoção de medida preventiva no sentido da remoção do acusado da casa da vítima em casos de violência 
doméstica. Contudo, ao deixar indefinido o conceito de violência doméstica, parte do judiciário se recusou a aplicar a medida, fundamentando-se no princípio da legalidade (nullum crimen sine lege certa). Já no segundo, a partir da Lei $\mathrm{n}^{\circ} 10.778$ passou a obrigar funcionários dos serviços público e privado de saúde a informar as autoridades legais quando da observância da ocorrência de violência doméstica em seus pacientes, além de estabelecer uma definição do conceito jurídico, em consonância com o disposto na Convenção Interamericana de prevenção, punição e erradicação da violência contra a mulher, ratificada pelo Brasil desde 1995.

Com a Lei $n^{\circ} 10.886$, a legislatura buscou criar uma qualificação do crime de lesões corporais, vinculando-a à prática de violência doméstica, ainda que de uma perspectiva neutra em relação a gênero, e com a ausência de quaisquer medidas alternativas, reforçando o entendimento de que a solução para o problema estaria na persecução penal. Em 2006, contudo, com a promulgação da Lei n 11.340, conhecida como "Lei Maria da Penha", o primeiro diploma legal brasileiro a sistematicamente dispor a respeito da violência doméstica, assumiu-se a nível legislativo a importância de serem mulheres as vítimas de violência doméstica, com a constituição de uma série de medidas de caráter não-penal, e o afastamento da competência das referidas cortes especializadas para casos de violência doméstica, em prol de jurisdições mais especializadas.

É possível dizer que a nível legislativo a Lei Maria da Penha significou uma absorção e tradução quase integrais das exigências dos movimentos feministas brasileiros. Contudo, quando de sua aplicação, as controvérsias em torno e a esse respeito tiveram consequências restritivas, conforme aponta Cecília MacDowell Santos. Nos primeiros anos, muitos magistrados decidiram pela inconstitucionalidade da lei, em exercício do controle difuso, por realizar uma distinção entre homens e mulheres, a seus olhos, inaceitável perante o direito à igualdade, com outros continuando a decidir pela competência das cortes especializadas. Decisões contraditórias se assomaram e a questão chegou ao Supremo Tribunal Federal, em um julgamento de resultados ambíguos, da perspectiva dos movimentos feministas, pois aquilo que deveria ter sido reconhecido pelos magistrados brasileiro, para uma parcela deles somente passou a ser observado, por uma imposição do STF, que sumulou a questão (SANTOS, 2010, p. 153-167).

Ao final, o que se percebe é que a compreensão hierarquizada das relações entre homens e mulheres tem difusão considerável, inclusive entre agentes estatais, bem como a 
interpretação de que a violência doméstica é um problema privado. Pese aos avanços, inclusive no âmbito de campanhas midiáticas incentivando as denúncias e representação contra os violadores, ainda há muito a se fazer.

Como denunciado pelo Índice de Desigualdade de Gênero, as mulheres no Brasil também enfrentam discriminação perante o mercado de trabalho, na forma de um círculo vicioso comum a países em desenvolvimento, a começar pelo baixo nível de escolaridade, o que as impede de galgar posições exigentes de maior qualificação, obrigando-as a procurar emprego no setor de serviços, ou no mercado informal (MENEZEZ; SORZAFAVE, 2017). Em relatório ao Comitê sobre Direitos Econômicos, Sociais e Culturais se apontou que em $20017 \%$ das mulheres do país nunca frequentaram uma escola, 60\% não chegaram ao segundo grau, com apenas $10 \%$ desse número tendo terminado o primeiro grau, com a taxa de desistência dos estudos entre as mulheres por volta de $18 \% .27 \%$ cursou o segundo grau, mas com apenas $16 \%$ desse total o tendo concluído. Apenas $6 \%$ das mulheres ingressaram no ensino superior e somente $3 \%$ se formaram, de modo que, então, apenas $1 \%$ das mulheres do Brasil se encontrava em cursos de pós-graduação (seguramente, então, menos de $0.2 \%$ em cursos de doutorado). ${ }^{1}$

Ainda que em dez anos esses números tenham melhorado significativamente, algumas discrepâncias continuam presentes, especialmente no que diz respeito à participação no mercado de trabalho, ganhos salariais, e a ocupação de posições de liderança em organizações e empresas. No geral, em 2004, apenas 30,5\% dos cargos de diretor-geral (CEO) eram ocupados por mulheres, concentradas em áreas como educação e seguridade social. E, em 2007, de acordo com a análise de Maria Cristina Aranha Bruschini (2007), as discrepâncias salarias entre homens e mulheres aumentavam conforme maior o tempo de estudo, dado que, entre aqueles homens e mulheres com 15 anos ou mais de estudo (o correspondente a um curso de ensino superior), $62 \%$ dos homens recebiam mais que cinco salários mínimos contra apenas $35 \%$ das mulheres.

Como sugerido acima, as mulheres ainda são típica e culturalmente vinculadas ao seu ciclo reprodutor, vistas basicamente como responsáveis por desempenhar funções voltadas à maternidade, a culminar nos índices discrepantes de atividades domésticas realizadas por cada um dos companheiros ou cônjuges de casais heterossexuais

\footnotetext{
${ }^{1}$ COMITÊ SOBRE DIREITOS ECONÔMICOS, SOCIAIS E CULTURAIS. Violence against Women in Brazil: A report to the Committee on Economic, Social, and Cultural Rights. 23 mai. 2003. Disponível em: < http://www.omct.org/files/2004/07/2409/eng_2003_02_brazil.pdf> Acesso em: 31 de janeiro de 2017.
} 
(BRUSCHINI, 2007). Mas não tão somente. Tais estereótipos estendem sua força, parcialmente contribuindo para o déficit de representatividade política das mulheres no Estado brasileiro.

Desde 1998 o Brasil adota cotas mandatórias (no mínimo 30\%) para candidaturas de mulheres em todos os níveis da federação. Todavia, dos quatro países analisados, é o que tem o menor número de assentos parlamentares ocupados por mulheres. Essa medida foi aprovada sem muito debate ou grandes controvérsias. À época, o próprio movimento feminista se mostrou dividido, por um lado enxergando-a positivamente, e por outro questionando sua capacidade de efetividade. Segundo Clara Araújo (2001), os parcos resultados não são causados tão somente pelo sistema eleitoral do país. Para a autora, amparada em análise comparada de outros países da América Latina com formação cultural parecida e que também adotaram cotas mandatórias, a falta de representatividade tem causas culturais e econômicas.

Primeiro, candidatas mulheres enfrentam sérias dificuldades em conseguir financiamento para suas campanhas, o que se explica tanto pelas discrepâncias do mercado econômico como pela sua ausência em posições de destaque, seja no setor privado, seja no setor público. Segundo, a ausência de quaisquer mecanismos de controle, sejam democráticos, sejam de ação afirmativa, da composição e funcionamento dos partidos, vistos com desconfiança por parte dos movimentos sociais, e, por sua vez, formado por uma ampla maioria de homens, em geral portados de visões estigmatizadas a respeito das mulheres, em que política apareceria como uma atividade pouco ou nada feminina. Tais fatores influenciam na apresentação das listas de candidatáveis, já que a cota para mulheres é calculada com base no número máximo de candidaturas que cada partido pode oferecer (em até $150 \%$ das vagas disponíveis). Como os partidos não são obrigados a apresentar o número máximo de candidatos, poucas são as listas que chegam aos $30 \%$ legalmente exigidos de candidaturas femininas (ARAÚJO, 2001).

Assim, fica evidenciado que as mulheres e os problemas por elas enfrentados ainda têm tido pouco espaço oficial no Brasil, portanto, apesar dos inegáveis avanços. A expectativa cultural da maioria dos homens (e de uma parcela conservadora significativa das próprias mulheres) ainda é de que permaneçam em casa (o local por excelência da resolução de todos e quaisquer conflitos em que se vejam envolvidas) ou dividam sua vida entre casa e trabalho, mas cuidando primeiro da casa. Malgrado a existência de inúmeras medidas 
legislativas e políticas públicas específicas a respeito, sem contar os mandamentos constitucionais de igualdade entre os gêneros, a cultura ainda arraigada, dificulta a efetivação dos direitos fundamentais de dignidade das mulheres, por vezes inclusive restringidos pelo próprio judiciário. Tanto do ponto de vista das condições de subsistência (veja-se as análises sobre as condições de trabalho da mulher); quanto ao ponto de vista da expressividade (vejase as dificuldades de serem ouvidas que apresentamos neste estudo); quanto do ponto de vista das condições de empoderamento (veja-se as análises sobre o espaço ocupado pelas mulheres nos cargos públicos); quanto, por fim, das condições de respeito (veja-se as explicações sobre as dificuldades do combate à violência doméstica no Brasil), em todas estas dimensões da dignidade, a promoção de direitos às mulheres ainda carece de avanços significativos no Brasil

\section{Considerações Finais}

A investigação aqui empreendida, em perspectiva comparada, dos direitos das mulheres e da desigualdade de gênero ainda existente nos países do BRICS, assim como, em geral, qualquer pesquisa que queira tratar do problema da efetividades de direitos fundamentais, não pode se dar na perspectiva tradicional do Direito Comparado (caracterizada pela relação comparativa entre normas abstratas, ou, no máximo, entre explicações doutrinárias abstratas acerca dessas normas abstratas, de diferentes países), mas em uma perspectiva de estudos interconstitucionais criticamente direcionados a busca por entender a experiência jurídica concreta de uma sociedade, para além do mero ordenamento jurídico dessa mesma sociedade. Ademais, buscou-se superar igualmente as superficialidades de leituras puramente externas da experiência jurídico-constitucional de um país, o que se deu pelo mergulho nas pesquisas de cunho sociológico, econômico e cultural existente acerca da situação das mulheres nesses países.

Assim como em todos países analisados, ao confrontarmos a nomologia constitucional oficial da Índia, com as práticas efetivas e dados concretos acerca da situação da mulher indiana, foi possível confirmar as disparidades importantes entre a normatividade oficial e a perpetuação de certas vivências tradicionais e religiosas, acabando por produzir nas políticas públicas e nas práticas governamentais de proteção e efetivação de direitos relacionados à mulher um grande hiato entre o que é declarado nas leis e a efetividade das relações estabelecidas. Constatamos, complementarmente, uma peculiar intensificação dessa 
discrepância quando da interiorização territorial das análises, quando, então, a Índia profunda cobra seu preço na configuração do estado da arte da efetivação de direitos às mulheres, perpetuando práticas de discriminação e violência, nesse país continental

O estudo da situação concreta da desigualdade de gênero na China, comparativamente empreendidos, enquanto técnica de aprofundamento crítico da análise sobre a inefetividade dos direitos das mulheres, permitiu constatar que o ato performático de declarar de direitos no plano nomológico chinês não implica necessariamente na garantia de sua exigibilidade como direito, nas situações concretas. Assim, verificou-se que, apesar de ser o país que aparentemente possui menos desigualdade de gênero (ao menos segundo os índices oficiais), a dificuldade que as mulheres enfrentam na china para a proteção de seus direitos são notórias. $\mathrm{Na}$ análise da situação das mulheres em território chinês constata-se que a existência de instruções e regulamentações burocráticas contrárias ou omissas quanto a exigibilidade de direitos de não-discriminação e de proteção previstos na Constituição torna tais direitos praticamente inexigíveis, quando incorretamente manejados pelo Estado. Assim, configura-se também na China um hiato entre declaração e promoção de direitos das mulheres. Esse hiato, porém, não se dá como no Brasil, por exemplo, onde, tal como vimos, declaram-se direitos e confirmam-se essas declarações nos planos infraconstitucionais, mas, ainda assim, tergiversa-se hermeneuticamente no plano da burocracia estatal e das relações privadas, de modo a não os respeitar e a não os fazer cumprir. O caso chinês não é o de um país que não cumpre suas leis (como nos parecer ser o caso brasileiro). O caso chinês é o caso de um país que cumpre suas leis, mas que enxerga os deveres nelas previstos como superiores e anteriores aos direitos, e as regulamentações administrativo-burocráticas como as balizas principais, onde a Constituição é apenas um símbolo de uma nova utopia (a do desenvolvimento econômico pleno), cuja busca justifica e legitima regras do dia-a-dia que contrariam a própria utopia constitucional, dentre elas, a indiferença acerca da discriminação da mulher.

De certa maneira, as análises feitas acerca do Brasil demonstram que há um avanço recente, porém ainda aquém do mínimo que se espera para que se constitua uma sociedade razoavelmente livre de preconceito e violência de gênero, no Brasil. Não fosse assim não seríamos apenas o nonagésimo quarto país no ranking de desigualdade de gênero.

\section{Referências Bibliográficas}


AMBEDKAR, Bhimrao Ramji. The rise and fall of Hindu woman. Jalandar: Bheem Patrika Publications, 1980; RAMECHAN, Anantanad. A Hindu Perspective. In: What Men Owe to Women: Men's Voices from World Religions. MAGUIRE, Daniel C.; RAINES, John C.. Albany: State University of New York Press, 2001.

BEGUM, Rasida. Violation of Women Rights in India. International Journal of Humanities \& Social Science Studies, v. 1, no 3, p. 216-224, 2014.

BEHAN, Charlotte L. In the Public Eye: Women in Early Twentieth-Century China. In: Women in China: Current Directions in Historical Scholarship. GUISSO, Richard W.; JOHANNESSEN, Stanley (Eds.). Youngstown: Philo Press, 1981.

BRUSCHINI, Maria Cristina Aranha. Trabalho e gênero no Brasil nos últimos dez anos. Cadernos de Pesquisa, v. 37, no 132, p. 537-572, 2007.

BURNETT, Jamie. Women's Employment Rights in China: Creating Harmony for Women in the Workplace. Indiana Journal of Global Legal Studies, v. 17, nº 2, 2010.

COELHO, Saulo de Oliveira Pinto. Para uma crítica das críticas ao discurso dos direitos humanos e fundamentais: da desconstrução do jushumanismo ao jushumanismo crítico. Revista de Direitos Humanos e Efetividade, v. 1, no 2, p. 01-18, 2015.

COMITÊ SOBRE DIREITOS ECONÔMICOS, SOCIAIS E CULTURAIS. Violence against Women in Brazil. 23 mai. 2003. Disponível em: <http://www.omct.org/files/2004/07/2409/eng_2003_02_brazil.pdf> Acesso em: 31 jan. 2017.

CORSINI, Eleonora. Women's Empowerment in India. 2012. Disponível em: $<$ http://www.luc.edu/media/lucedu/prolaw /documents/pdfs/3studentjournalcorsinil. pdf $>$. Acesso em 25 de janeiro 2017.

COSSMAN, Brenda; KAPUR, Ratna. Women and Poverty in India: Law and Social Change. Canadian Journal of Women and the Law, v. 6, 1993.

DUSCHE, Michael. Women's Rights in India: Hierarchical Ethics versus Egalitarian Morality. South Asia Chronicle, v. 4, p. 228-253, 2014.

GUPTA, Nidhi. Women's Human Rights and the Practice of Dowry in India. The Journal of Legal Pluralism and Unofficial Law, v. 35, nº 48, p. 85-123, 2003.

HAN, Anne M. Holding-up more than half the sky: marketization and the status of women in China. International Journal of Contemporary Legal Issues, $\mathrm{n}^{\mathrm{o}}$ 11, p. 791-810, 2001.

HERSHATTER, Gail. Women in China's Long Twentieth Century. California: University of California Press, 2007.

JAVEED, Shayan; MANUHAAR, Anupam. Women and Wage Discrimination in India: A Critical Analysis. International Journal of Humanities and Social Science Invention, v. 2, no 4, p. 06-12, 2013.

JOSÉ, Justin. P. Identity and Social Exclusion of Dalit Women: A psychosocial perspective. Contemporary Voice of Dalit, v. 8, no 2, p. 136-162, 2016.

LIU, Bohong [et al]. Reconciling work and Family: Issues and policies in China. A Working Report to International Labour Organization. Genebra: International Labour Organization Office, 2008. 
LIVNE, Emma. Violence Against Women in India: Origins, Perpetuation and Reform. 2015. Disponível em: <http://www.cmu.edu/hss/globalstudies/images/livne-gs-capstonepaper. pdf $>$. Acesso em: 25 de janeiro de 2017.

LOPES, Cristiane Maria Sbalqueiro. Direito do trabalho da mulher: da proteção à promoção. Cadernos Pagu, v. 26, p. 405-430, 2006.

LU, Jiefeng. Regulating employment discrimination in China: a discussion from the sociolegal perspective. Michigan State International Law Review, v. 23, no 2, p. 437-457, 2015 .

MENEGHEL, Stela Nazareth; HIRAKATA, Vania Naomi. Femicides: female homicide in Brazil. Revista Saúde Pública, v. 45, nº 3, 2011.

MENEZES FILHO, Naercio; SCORZAFAVE, Luiz. Employment and inequality outcomes in Brazil. 2007. Disponível em: 〈https://www.oecd.org /employment/emp/42546065.pdf> Acesso em: 31 janeiro de 2017.

MULLALY, Siobhan. Feminism and Multicultural Dilemmas in India: Revisiting the Sha Bano Case. Oxford Journal of Legal Studies, v. 24, nº 4, p. 671-692, 2004.

OGLETREE, Charles; ALWIS, Rangita de Silva-de. When Gender Differences Become a Trap: The Impact of China's Labor Law on Women. Yale Journal of Law \& Feminism, v. $14, \mathrm{n}^{\mathrm{o}} 1$, p. $77-78,2002$.

ONSRUD, H.; PAIXÃO, S.; NICHOLS, S. Women and Land Reform in Brazil. [Relatório técnico n. 239] Department of Geodesy and Geomatics Engineering - University of New Brunswick, Canadá, 2005.

ORGANIZAÇÃO DAS NAÇÕES UNIDAS (ONU). Gender Inequality Index. 2014. Disponível em: <http://hdr.undp.org/en/composite/GII>. Acesso em: 20 de janeiro de 2016.

ORGANIZACIÓN DE LAS NACIONES UNIDAS (ONU). Informe del Grupo de Trabajo sobre el Examen Periódico Universal: China (incluidos Hong Kong (China) e Macao (China)). Consejo de Derechos Humanos, $25^{\circ}$ período de sesiones, 2013.

PARTIDO COMUNISTA CHINÊS. The Common Program of the Chinese Peoples Political Consultative Conference. 29 set. 1949. Disponível em: <http://echaupak.net/database/chicon/1949/1949e.pdf> Acesso em: 20 de janeiro de 2017.

RANDALL, Vicky. Legislative gender quotas and Indian Exceptionalism: The Travails of the Women's Reservation Bill. Comparative Politics, v. 39, nº 1, p. 63-82, 2006.

REPÚBLICA DA ÍNDIA. 2011 Census of India. 20 de maio de 2013. Disponível em: <http://censusindia.gov.in/>. Acesso em: 25 de janeiro 2017.

REPÚBLICA POPULAR DA CHINA. Law on the Protection of Women's Rights and Interests of the People's Republic of China. 3 abr. 1992. Disponível em: <https://www.justice.gov/sites/default/files/eoir/legacy/2013/11/08/Protection\%20of $\%$ 20Women's\%20Rights.pdf $>$. Acesso em: 20 de janeiro de 2017.

REPÚBLICA POPULAR DA CHINA. Labour Law of the People's Republic of China. 5 jan. 1994. Disponível em <http://www.npc.gov.cn/englishnpc/Law/200712/12/content_1383754.htm>. Acesso em: 20 de janeiro de 2017. 
RIMASHEVSKAYA, Natalia. Gender relationships and gender policy in contemporary conditions. Intellectual Economics, v. 7, nº1, p. 54-62, 2013.

WEI, Dan. Um olhar sobre relações laborais em mudança na China. Boletim da Faculdade de Direito, Coimbra, v. LXXXV, p. 261-277, 2009.

ZUO, Jiping. Work and Family in Urban China: Women's Changing Experience since Mao. Nova Iorque: Palgrave Macmillan, 2016. 